\title{
Desenvolvimento de produto de auxílio à fisioterapia respiratória e de estimulação visual de crianças com a Síndrome Congênita associada ao Vírus Zika
}

\author{
Product development for respiratory physiotherapy support and visual \\ stimulation for children with Zika Virus Congenital Syndrome
}

\author{
ALMEIDA, Mariana \\ Universidade Federal Fluminense, Graduanda em Desenho Industrial \\ almeidamariana198@gmail.com \\ RODRIGUES, Lorena \\ Universidade Federal Fluminense, Graduanda em Desenho Industrial \\ lorenarodriiguessp@gmail.com \\ AMADO, Giuseppe \\ Universidade Federal Fluminense, Doutor em Design \\ gamado@id.uff.br

\section{BITTENCOURT, João Marcos} \\ Universidade Federal Fluminense, Doutor em Engenharia de Produção \\ joaombittencourt@gmail.com
}

\section{RESUMO}

A proposta deste trabalho foi de criar um produto novo com foco na tecnologia assistiva. Este, define-se como uma cadeira de auxílio a fisioterapia respiratória e de estimulação visual de crianças, na faixa etária de 0 a 3 anos, com Síndrome Congênita Associada ao Vírus Zika (SCZKV). O método utilizado para o desenvolvimento tem o suporte da intervenção Ergonomizadora através de visitas periódicas e diálogos dentro de um instituto de fisioterapia e reabilitação, com o acompanhamento do tratamento de uma criança diagnosticada com tal síndrome. O trabalho adequou-se para a realização do tratamento, mantendo a coluna da paciente alinhada e também exemplifica como o design é uma ferramenta de inclusão. 


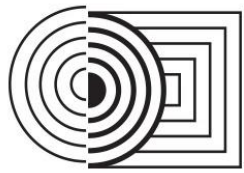

$17^{\circ}$ ERGODESIGN \& USIHC 2019

PUC-Rio, 11 a 13 de dezembro

Rio de Janeiro, RJ, Brasil $17^{\circ}$ Ergodesign - Congresso Internacional de Ergonomia e Usabilidade de Interfaces Humano Tecnológica: Produto, Informações Ambientes Construídos e Transporte

$17^{\circ}$ USIHC - Congresso Internacional de Ergonomia e Usabilidade de Interfaces Humano Computador

\begin{abstract}
The proposal of this work was to create a new product that focus on assistive technology. The product, define itself as a supportive chair to respiratory physiotherapy and visual stimulation for children, at the age of 0 to 3 years, with Zika Virus Congenital Syndrome (ZVCS). The method used for the development has the support of the Ergonomizer intervention through periodic visits and dialogs inside a physiotherapy and rehab institution, with the monitoring of the treatment of a child diagnosed with such sindrome. The work was adapted to the realization of the treatment, keeping the patient spine aline and also exemplified how the design is a inclusive tool.
\end{abstract}

Assistive Technology, Ergonomics, Design, Physiotherapy, Participatory Design

\title{
1. INTRODUÇÃO
}

De acordo com o Instituto Brasileiro de Geografia e Estatística (IBGE, 2012), mais de 45 milhões de brasileiros apresentam algum tipo de necessidade especial, seja essa física, mental, auditiva, visual ou múltipla. Dentre eles, 13,3 milhões de habitantes possuem algum grau de deficiência motora. Sendo, $46,4 \%$ das pessoas com deficiência em idade ativa recebem até um salário mínimo ou não possuem rendimento, sendo que entre a população geral esse valor é de $37,1 \%$ (Dallegrave, 2014). "Para as pessoas sem deficiência a tecnologia torna as coisas mais fáceis. Para as pessoas com deficiência, a tecnologia torna as coisas possíveis".

(RADABAUGH, 1993). Define-se Tecnologia Assistiva (TA) como todos os recursos e serviços que contribuem para proporcionar ou ampliar habilidades funcionais de pessoas com deficiência e conseqüentemente promover vida independente e inclusão (BERSCH \& TONOLLI, 2006). Visto na Pesquisa Nacional de Tecnologia Assistiva (TA), na sua versão 2007-2008, sugere-se que há grande desatenção para essa área, o que aumenta as dificuldades em relação ao acesso aos recursos de Tecnologia Assistiva. A Síndrome Congênita do Zíka Vírus (SCZKV) é um padrão único de deficiências congênitas e incapacidades encontradas em fetos e bebês infectados pelo vírus durante sua gestação. Segundo a Organização Mundial de Saúde (OMS) e o Ministério da Saúde, entre os anos de 2015 e 2017 foram confirmados no Brasil aproximadamente 3037 casos de crianças infectadas, sendo que menos de $1 / 3$ (aproximadamente 856) delas recebem tratamento público. Estes dados sugerem a dificuldade encontrada por profissionais e familiares na realização de suas atividades com os pacientes.

Dentre as condições dessa síndrome, encontre-se a dificuldade relacionada a respiração. Crianças e bebês infectados possuem um comprometimento neuropsicomotor, que consequentemente levam a alterações respiratórias. Quanto maior o comprometimento motor maior a incidência de disfunções respiratórias.

O Reequilíbrio Toracoabdominal (RTA) é uma técnica de terapia manual que incentiva a ventilação pulmonar promovendo a remoção de secreção das vias aéreas. Sua técnica consiste no alongamento e fortalecimento dos músculos respiratórios através da fisioterapia. A fisioterapia respiratória em crianças se difere do método utilizado em adultos e varia de acordo com a doença pulmonar de que se trata, com a condição clínica do paciente incluindo a análise da adequação da criança ao tratamento e ao desenvolvimento neuropsicomotor, tendo em vista os atrasos e má formações. $O$ uso do design como ferramenta para inclusão e melhora na 


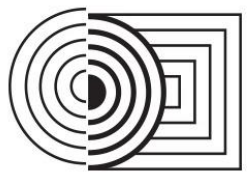

\section{$17^{\circ}$ ERGODESIGN \& USIHC 2019 \\ PUC-Rio, 11 a 13 de dezembro \\ Rio de Janeiro, RJ, Brasil}

$17^{\circ}$ Ergodesign - Congresso Internacional de Ergonomia e Usabilidade de Interfaces Humano Tecnológica: Produto, Informações Ambientes Construídos e Transporte

$17^{\circ}$ USIHC - Congresso Internacional de Ergonomia e Usabilidade

de Interfaces Humano Computador

qualidade de vida é uma área notória quando uma criança atinge um objetivo. Por menor que ele possa parecer, torna seu crescimento e progresso mais visíveis.

Neste trabalho, é relatado o caso de desenvolvimento de um produto focado no tratamento respiratório de crianças com SCZKV. O projeto foi desenvolvido com base no método de análise e desenvolvimento em Ergonomia (Moraes e Mont'alvão, 2010). O objetivo é apresentar uma solução para a dificuldade que familiares e profissionais da área de saúde, na realização do tratamento respiratório, encontram quando tentam posicionar as crianças em cadeiras comuns ou aquelas adaptadas, porém majoritariamente de forma ineficaz. Os encostos de cadeiras em sua grande maioria, assentam-se apenas para o apoio do corpo, exigindo de seu usuário que 0 mesmo consiga suportar seu próprio peso apoiado ali. Como essas crianças não possuem controle da cabeça e de seu tronco, não suportam seu próprio peso, o uso de cadeiras comuns é inadequado e ineficiente quando o objetivo é dar suporte à essas crianças. As cadeiras adaptadas para crianças que vivem essa dificuldade, por vezes não são eficazes, uma vez que por serem produzidas em larga escala, não são específicas e não se adequam ou suprem as necessidades de cada criança.

Este projeto insere-se dentro do contexto de parceria do grupo do projeto e um instituto de fisioterapia e reabilitação. O caso foi selecionado dentro do espaço de fisioterapia infantil, que manifestou grande necessidade de doação de recursos. $O$ cenário envolve o tratamento respiratório destas crianças, que precisam reorganizar seu equilíbrio toracoabdominal através de exercícios coordenados pelos profissionais, em uma sala compartilhada com demais pacientes em tratamentos diferentes. Para um entendimento do que poderia ou não ser feito, longas conversas foram essenciais para a proposta de um produto que permitisse a realização do tratamento sem interrupções.

\section{MÉTODO}

O grupo de quatro projetistas reuniu-se para trabalhar em parceria com um instituto de fisioterapia e terapia ocupacional, em conjunto com dois orientadores de projeto, que auxiliavam nas propostas ergonômicas e de design, e duas profissionais da área de saúde, que auxiliavam nas orientações sobre as deficiências, suas dificuldades e tratamentos para a conduta dos exercícios respiratórios de pacientes diagnosticados com a SCZKV através de tecnologia assistiva. Deu-se por visitas periódicas ao local, acompanhando as sessões e o tratamento das pacientes. A análise foi centrada em dois pacientes para poder construir uma compreensão dos problemas relativos ao tratamento selecionado com a equipe do instituto. $O$ projeto teve duração de quatro meses em que foram realizadas as visitas, a proposição de um produto e seu teste.

O método utilizado pelo grupo para a análise e desenvolvimento do projeto foi da Intervenção Ergonomizadora (Moraes e Mont'alvão, 2010). Pois este, permite uma investigação da circunstância do trabalho tornando possível argumentar e propor modificações que melhorem a qualidade de vida das pacientes. As fases do método envolvem o apreciação ergonômica, diagnose, projetação ergonômica e validação ergonômica. A apreciação ergonômica deste trabalho compreendeu a ilustração dos problemas encontrados durante o acompanhamento das sessões, concluindo a hierarquização dos problemas a serem diagnosticados. A diagnose 


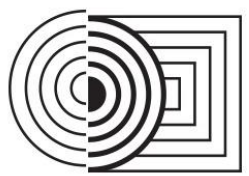

\section{$17^{\circ}$ ERGODESIGN \& USIHC 2019 \\ PUC-Rio, 11 a 13 de dezembro \\ Rio de Janeiro, RJ, Brasil}

$17^{\circ}$ Ergodesign - Congresso Internacional de Ergonomia e Usabilidade de Interfaces Humano Tecnológica: Produto, Informações Ambientes Construídos e Transporte

$17^{\circ}$ USIHC - Congresso Internacional de Ergonomia e Usabilidade

de Interfaces Humano Computador

deu- se por uma análise mais profunda dos problemas priorizados considerando o ambiente em que as sessões ocorriam e os dados coletados.

Os dados para esse projeto foram coletados através da observação direta da realização de consultas com os pacientes. O registro das consultas analisadas foram feitos com fotografias e notas de caderno. Após algumas consultas, foram realizadas entrevistas com os profissionais e familiares para melhor compreender as dificuldades observadas e debater as prioridades para esse trabalho. Detalhou-se as dimensões, características físicas, componentes e arranjos para criação do protótipo, propondo melhorias para o tratamento respiratório, durante a realização da projetação ergonômica.

Para etapa de validação, foram organizadas visitas com propósito de avaliar o tempo em que as pacientes permaneciam na cadeira e como se mantinham conforme o tratamento acontecia. As pacientes compareceram ao instituto, sem alterarem suas rotinas, para realização de seus tratamentos. Em cada visita foi dada toda a orientação necessária dos profissionais da área de fisioterapia e terapia ocupacional caso houvesse a necessidade de mudanças ou alterações no produto para que melhor se adaptasse às usuárias. O produto foi utilizado pela paciente principal do acompanhamento e por outra, com patologia similar.

Optou-se por desenvolver o trabalho em um abordagem participativa, envolvendo os usuários na compreensão dos problemas e desenvolvimento das soluções. O lema da TA "Nada sobre nós, sem nós" é amplamente divulgado e utilizado por profissionais da área e deficientes e foi aplicado durante todo o processo. Ele expressa ideia de que nenhuma política deveria ser decidida por ninguém sem a direta participação dos membros do grupo que são atingidos por essa política. A mentalidade e atitudes seguidas, abrem espaço para criação conjunta com quem vive de fato as dificuldades, incluindo todo o sistema envolvido, construindo a partir das necessidades do outro, compreendendo o âmbito das questões sociais em que se insere 0 trabalho e projetar de forma eficaz para a complexidade em que se enquadra.

\section{RESULTADO}

Nesse item serão apresentados o resultados nas análises do trabalho, assim como o produto desenvolvido e sua validação.

\subsection{Situação da análise}

O tratamento acompanhado foi de Reequilíbrio Toracoabdominal. Como já citado, esse tratamento consiste em incentivar a ventilação pulmonar, promover a remoção de secreções, alongar e fortalecer os músculos respiratórios. Para efetuar esta tarefa a médica coloca a criança no apoio triangular fisioterapêutico com inclinação fixa de 30 graus e um rolinho nas pernas, de forma a manter os joelhos dobrados. Antes de iniciar o trabalho com a criança a fisioterapeuta coloca uma toalha pessoal da paciente, dado que o apoio pertence ao instituto e é utilizado por diversas crianças que são atendidas dentro do local. Inicialmente ela realiza os procedimento de escutar coração e pulmão para analisar o grau de gravidade do estado da paciente. Após a análise, ela certifica-se da postura correta e coloca as mãos no corpo da criança, de maneira a segurar o tronco para iniciar as massagens. Essas são ritmadas, 
acompanhando a respiração da paciente. Quando a mesma inspira, as mão da fisioterapeuta sobem pela sua costela e peito e, ao expirar, é efetuado o movimento contrário.

Durante o tratamento constatou-se dificuldades relacionadas à postura. Observou-se que a cabeça insiste em cair para os lados e para frente, visto que o encosto é isento do suporte necessário, fazendo com que a profissional necessite pausar o tratamento para ajustá-la na posição correta diversas vezes. Observou-se também que durante o tratamento, ocasionalmente a paciente tinha ataques de epilepsia e espasmos nas pernas, que são obstáculos para o curso da sessão, uma vez que também alteram a postura da criança. Utilizase, na tentativa de manter suas pernas mais fixas, um rolinho por trás dos seus joelhos, mas que do mesmo modo que os encostos, não são eficazes.

Dentro do setor, há uma grande dificuldade encontrada quando se trata de apoio para tronco, cabeça e corpo das crianças. Foram encontrados bancos comuns, cadeiras adaptadas de forma ineficiente e demais recursos improvisados pelos fisioterapeutas do instituto. Visto que a paciente não tem controle de sua cervical e tronco, ao apoiar-se nesses encostos comuns ou improvisados, ela encontra-se desconfortável e inquieta. A ausência desse suporte pede auxílio de demais pessoas no ambiente (sejam essas, profissionais ou familiares) para mantê-la na postura adequada para realização do tratamento.

Além de desperdiçar parte do tempo da sessão na adequação da postura, o local de trabalho não possui um armazenamento adequado para tais apoios, deixando-os na conclusão do atendimento, encostados no final da sala. Ademais, a sala por ser compartilhada muitas vezes está lotada e o transporte dos recursos torna-se algo cansativo e preocupante.

Figura 1 - Fisioterapeuta ajustando as pernas da paciente para início da sessão.

Fonte: Autoral. 2019

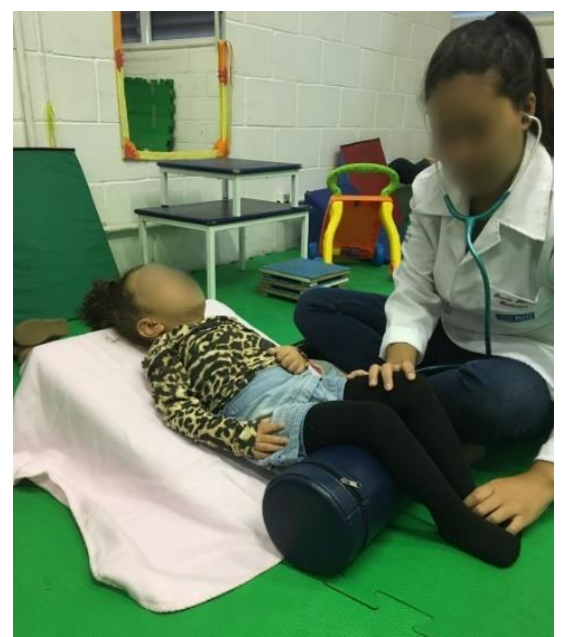

Figura 2 - Fisioterapeuta ajustando a cabeça da paciente na posição correta, para continuar o exercício. 


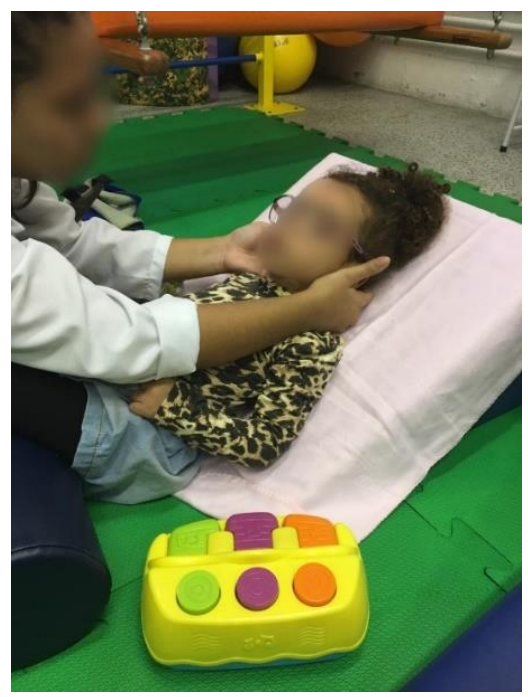

\subsection{Proposta do projeto}

O conceito do trabalho era do desenvolvimento de um produto que auxiliasse a fisioterapia respiratória provendo estabilidade e conforto do tronco e da cervical da criança, com um aspecto infantil, em conjunto com o uso de cores contrastantes e regulagem na inclinação do tronco, fornecendo uma maior gama de possibilidades de técnicas de tratamento. Para ser resistente e permitir estabilidade, a estrutura de madeira que fica por baixo do assento e a base da regulagem contam com $3 \mathrm{~cm}$ de espessura, da mesma maneira que a estrutura por trás do encosto. Essa, porém, vazada na medida em que não se perde resistência e permite que 0 produto torne-se mais leve. Para não ferir a saúde da paciente e tornar-se confortável, amarrase na estrutura uma espuma forrada com um tecido antiderrapante. O suporte que evita a instabilidade da criança dá-se por meio de rolinhos preenchidos com isopor pérola presos por velcro no acolchoado e duas faixas elásticas, uma para cabeça presa por costura no acolchoado do encosto e outra para o quadril, sendo esta removível (ambas opcionais).

Visando melhores possibilidades de reorganização da biomecânica respiratória, o produto permite 3 regulagens diferentes para seu uso, sendo a primeira a mais perto de sessenta graus, a segunda intermediária e a terceira próxima de trinta graus, facilitando tanto nos exercícios fisioterapêuticos quanto em outras tarefas exercidas para a paciente, desta forma diminuindo as possibilidades de agravamento de seu quadro além de facilitar no posicionamento e postura da fisioterapeuta e da mãe da criança ao executarem as atividades. A possibilidade de regular o encosto da cadeira permite que as profissionais apliquem técnicas variadas de tratamento respiratório, além de aumentar o conforto da criança, adaptando-se a suas necessidades, mantendo a postura correta, evitando danos às colunas. Todos os componentes produzidos tornam-se essenciais para o bem-estar das usuárias.

Por tratar-se de um mobiliário infantil, foi importante trazer a temática para dentro do projeto. Dado que a SCZKV afeta a visão de seus portadores, a infantilização do produto utilizando a temática do inseto abelha, levou ao uso do maior contraste dentro do círculo cromático: preto e amarelo. Posto isso, transforma-se a abelha em um inseto amigável e afetivo, em que a criança se sinta confortável e acolhida. Por moldar-se no corpo de seus usuário em conjunto 
personificação, o produto transmite o sentimento de acolhimento, de abraço e conforto da criança. Denomina-se Comfy Bee.

Figura 3 - Foto do produto.

Fonte: Autoral. 2019

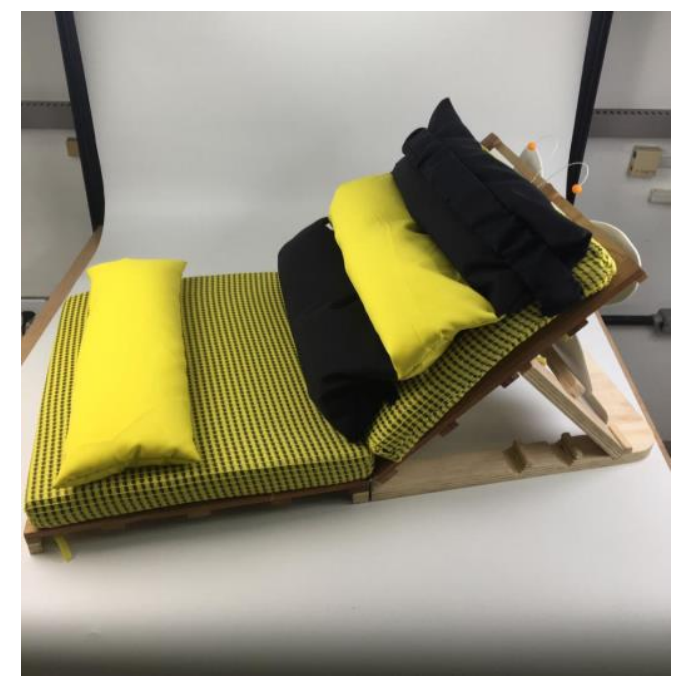

\subsection{Validação}

Para evidenciar se o produto atendeu as expectativas, as crianças foram posicionadas sentadas sobre ele já montado, utilizando a faixa para dar suporte à cabeça e a outra ao quadril. Verificou-se que cada paciente se adequou bem à cadeira, sem que o corpo escorregasse pelo tecido, a cabeça e o tronco se mantiveram estáveis e, com isso, não houve incômodos para os usuários. Apenas uma das pacientes utilizou a faixa para a cabeça, ambas utilizaram o rolinho da perna e nenhuma das duas necessitou da faixa do quadril. A paciente que utilizou da faixa de suporte à cabeça, não sentiu incômodo, nem desconforto, uma das preocupações tomadas ao projetá-las, mantendo-se estável durante todo o procedimento. Juntamente as regulagens feitas para o uso da cadeira, cada material foi escolhido pensando nesse bem-estar trazendo facilidades para o tratamento do RTA, sendo este o fator que mais chamou atenção dos projetistas devido às dificuldades encontradas durante a realização do método. O tratamento de ambas, então, ocorreu sem interrupções para adequação de postura, permitindo aproveitamento do tempo total da sessão. Constatou-se que além de dar o suporte desejado para realização das atividades de fisioterapia respiratória, o produto dá assistência para demais atividades na vida das crianças, como a alimentação, interação com brinquedos, dinâmicas para estímulos visuais etc. Sua estrutura dobrável e com peças removíveis também foi extremamente útil para facilitar a locomoção e armazenamento, ocupando menos espaço em casa ou no ambiente de tratamento.

Apesar da faixa etária em que o produto se insere, também houve interesse de demais pacientes do instituto para seu uso. Pacientes não envolvidos no estudo do projeto e também 
que não estavam realizando tratamentos similares, sentiram-se atraídos e desejaram fazer uso do produto. O projeto tornou possível que apesar das grandes diferenças de corpo e tamanho de diversos pacientes, não só originadas de suas idades, mas também de suas patologias, 0 uso do produto, dado que seu encosto molda-se a cada corpo. Averiguou-se também a facilidade de armazenamento do produto. A estrutura que consiste em ser parte desmontável e parte removível, permite maior facilidade para organização ao final do tratamento. Evitando consequentemente que seu transporte seja de maior dificuldade.

Figura 4 - Produto sendo utilizado por paciente de 1 ano.

Fonte: Autoral. 2019

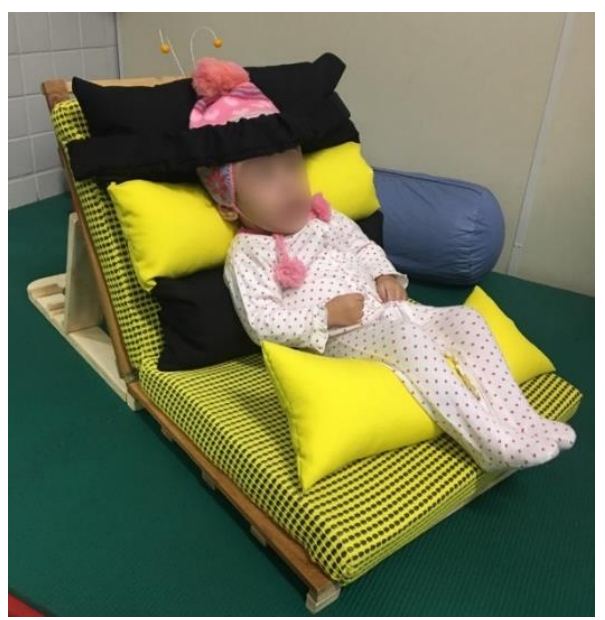

Figura 5 - Produto sendo utilizado por criança de 3 anos.

Fonte: Autoral. 2019

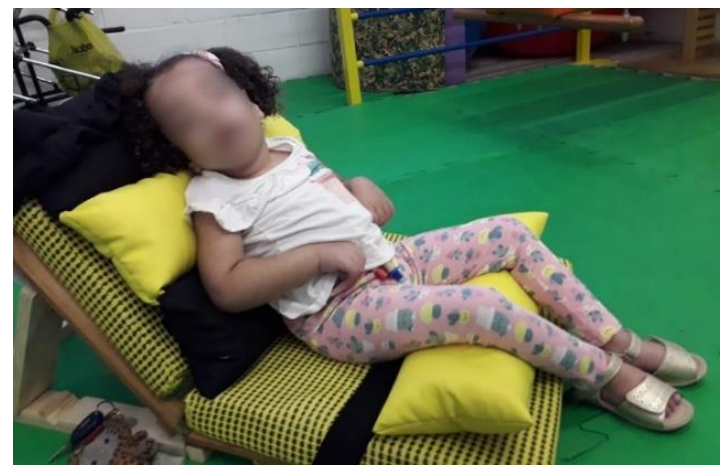

\section{DISCUSSÃO}




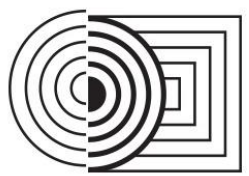

\section{$17^{\circ}$ ERGODESIGN \& USIHC 2019 \\ PUC-Rio, 11 a 13 de dezembro \\ Rio de Janeiro, RJ, Brasil}

$17^{\circ}$ Ergodesign - Congresso Internacional de Ergonomia e Usabilidade de Interfaces Humano Tecnológica: Produto, Informações Ambientes Construídos e Transporte

$17^{\circ}$ USIHC - Congresso Internacional de Ergonomia e Usabilidade

de Interfaces Humano Computador

A proposta deste trabalho com a criação da cadeira Comfy Bee foi trazer um auxílio na fisioterapia respiratória de crianças com a SCZKV. O produto foi recebido pelos profissionais, responsáveis e pacientes de maneira ampla e engrandecedora, mostrando toda satisfação com os resultados obtidos pelo uso do produto.

Quando trata-se de crianças com deficiências, toda conquista torna-se maior. O que para grande maioria das crianças é aprendido e conquistado com mais facilidade e a tecnologia serve apenas para tal, dentro dos padrões esperados de suas idades, apenas torna-se possível para essas dependentes através dos recursos que a tecnologia pode oferecer em conjunto com profissionais de diversas áreas, além de dedicação e força. A gratificação dos pais e responsáveis ao verem seus filhos confortáveis em algo considerado tão simples, neste caso o ato de sentar, recebendo o tratamento de maneira adequada, foi amplamente expressada durante as consultas voltadas à validação do produto. O método do design participativo permite a experiência do apoio direto ao desenvolvimento dessas crianças. Os pais demonstraram interesses pessoais de aquisição do produto, para levar esse conforto proporcionado para outras atividades realizadas em seus domicílios.

A descrição das técnicas e práticas vivenciadas nesses meses de desenvolvimento desvendam a importância de romper barreiras quanto ao medo do campo não explorado entre a relação de Ergodesign e TA. O projeto trouxe uma série de vantagens para as pacientes, promovendo o melhor conforto e estabilidade da cabeça e tronco, facilitando a conduta dos exercícios durante as sessões permitindo desta forma que não houvesse interrupções durante toda a sessão de tratamento e, com isso, otimizando seu tempo, além de facilitar seu transporte e armazenamento por ter a estrutura dobrável e desmontável.

Ressalta-se que por tratar-se de uma matriz produzida de maneira manual, questões como materiais e adequações aos usuários, poderiam ser melhor solucionadas uma vez que produzido industrialmente. Além de maior tempo para validação, podendo observar minuciosamente seu uso nas demais atividades mencionadas.

Como averiguado através das pesquisas, a busca por tratamento público mantém-se em grande crescimento. Referindo-se aos dados postos na introdução deste trabalho, nota-se a real demanda dessa área interdisciplinar de desenvolvimento de produtos voltados à tecnologia assistiva. O fortalecimento da relação de ergonomia e design, traz soluções inovadoras para os obstáculos e impasses da vida de pessoas deficientes. Podendo trazer independência, inclusão social e qualidade de vida, nas áreas de educação, realização de tarefas diárias, acessibilidade, recreação etc.

\section{CONCLUSÃO}

Constata-se que dentro da área de tratamentos fisioterápicos respiratórios, existem diversas dificuldades e limitações, como o risco de infecções e internações, especialmente em pacientes críticos. Nesses pacientes a fisioterapia é usada meio para prevenir a fraqueza muscular e recuperar a capacidade funcional. Profissionais da área de saúde, principalmente da rede pública, buscam por auxílio na solução de impasses que decorrem de patologias diversificadas 
que necessitam de apoio neste âmbito respiratório. Profissionais da área de saúde, principalmente da rede pública, buscam por auxílio na solução de impasses que decorrem de patologias diversificadas. Nota-se então a amplitude de possibilidades na realização de trabalhos futuros para o auxílio no tratamento de crianças com tais dificuldades, quebrando as fronteiras que limitam essa parcela da população. Esse trabalho manifesta a importância da interdisciplinaridade das áreas de saúde, reabilitação e Ergodesign, ficando evidente quando causam impactos positivos na vida dos pacientes. O Ergodesign tem como proposta criar um produto de acordo com as necessidades e características específicas de seu usuário proporcionando o bem-estar físico, psicológico e aumentando sua qualidade de vida. Considerando o tempo em que a criança deve permanecer sentada devido sua patologia, surge a importância de uma cadeira adequada para lhe proporcionar melhores condições de conforto e evitar maiores danos à sua saúde, cirurgias, complicações etc. Devido a isso, Comfy Bee foi criada com o objetivo de sanar a problemática e trazer esse conforto aos pacientes que sofrem das complexidades dessa síndrome e semelhantes, além de possuir estética de acordo com a faixa etária dos usuários.

Este campo da tecnologia assistiva, ainda muito pouco explorado, permite a criação de novos projetos através de uma rede colaborativa que projeta para as complexidades do mundo, trazendo para as pessoas deficientes melhoras na qualidade de vida, facilitando seus tratamentos, reabilitação e amenizando suas dificuldades.

\section{REFERÊNCIAS BIBLIOGRÁFICAS}

SARTORETTO, Mara Lúcia; BERSCH, Rita. O que é Tecnologia Assistiva?. Disponível em: http://www.assistiva.com.br/tassistiva.html. Acesso em: 2019.

SASSAKI, Romeu Kazumi. Nada sobre nós, sem nós: Da integração à inclusão. Disponível em: http://www.bengalalegal.com/nada-sobre-nos. Acesso em: 22 jun. 2011.

BLOG FISIOTERAPIA. Saiba Tudo Sobre a Fisioterapia Respiratória na Pediatria. Disponível em: https://blogfisioterapia.com.br/fisioterapia-respiratoria-na-pediatria/. Acesso em: 18 mai. 2017.

FÓRUM DA CONSTRUÇÃO. Ergonomia: Características da boa cadeira. Disponível em: http://www.forumdaconstrucao.com.br/conteudo.php?a=40\&Cod=763. Acesso em: [20--].

GALVÃO FILHO. A Tecnologia Assistiva: de que se trata?. Disponível em: http://www.galvaofilho.net/TA_dequesetrata.htm. Acesso em: 2009.

MORAES, Anamaria de; MONT'ALVÃO, Claudia. Ergonomia: Conceitos e aplicações. 4. ed. rev. atual. e aum. Teresópolis: 2AB, 2012. 223 p. v. 1. ISBN 978-85-86695-49-0.

OPAS. Infecção pelo vírus Zika. Disponível em: https://www.paho.org/bireme/index.php?option=com_content\&view=article\&id=312:infeccaopelo-virus-zika\&ltemid=183\&lang=pt. Acesso em: [20--]. 
RTA ONLINE. Técnica. Disponível em: https://rtaonline.com.br/o-metodo/tecnica/. Acesso em: [20--].

MELO, Débora. Mais de $\mathbf{4 5}$ milhões de brasileiros têm alguma deficiência; 9,5 milhões são idosos. Disponível em: https://noticias.uol.com.br/cotidiano/ultimas-noticias/2012/06/29/idosose-mulheres-sao-maioria-entre-portadores-de-deficiencia-aponta-ibge.htm. Acesso em: 29 jun. 2012. 